Early in this century it was recognized that the poorer people were suffering in health through lack of means to obtain medical advice and treatment. The National Health Insurance Act provided a form of health service for wageearners, while the infant welfare clinics, antenatal clinics, and other schemes were developed, mostly through borough councils. to provide free medical advice and limited treatment to those outside the National Health Insurance scheme who were in greatest need.

I believe that the local authorities undertook this, not because the general practitioners were doing their work badly, but because the poorer people could not afford to pay a doctor and only consulted one when illness became incapacitating. For this same reason there were not enough general practitioners to do the work that was needed. Since 1948 the National Health Service has relieved patients of the financial burden and so the original necessity for the local authority services, now largely transferred to the county councils, no longer exists, yet these services continue as an alternative to, and sometimes in competition with, the general-practitioner service. Is this overlap an economic or satisfactory arrangement?

I have heard it reiterated, and again by our President, that the overall policy of the Health Service outside the hospitals is that the general practitioner should be the leader of a team supplying services to the home. Present arrangements and developments appear to me to be working against this policy, and towards establishing the county medical officer of health in the leadership. But he is too remote from the individual patients to fulfil this position; at the same time the borough medical officer of health, so readily accessible to local practitioners, is a wasted asset. I do not wish to suggest that all the local authority's work should be handed over to the general practitioners-there are still not enough of them to do it all-but I do suggest that more should be done to develop the general-practitioner service. This service is handicapped at the outset because the doctor must provide premises, staff, and equipment out of his salary, while the local authority services are relatively lavishly provided for out of public funds.

One of the graver disadvantages of the local authority services is that the doctors who work in the clinics (with certain exceptions) never visit the patient's home, nor are they generally in touch with the family doctor. This is why the health visitor, their sole contact with the home, is so important to the local authority and of minor importance to the general practitioner. I have recently received a letter encouraging me to make more use of the health visitors, but as a family doctor I have very little real need for them, for in those cases where I could use them some other department or organization, to which I have direct access, supplies the need. Abolish wasteful use and overlap and I doubt the necessity of enrolling an additional 3,500 badly needed nurses as health visitors, which is what the Working Party recommends. It also recommended that co-operation between health visitors and general practitioners be improved, but I would go further and say that co-operation between all local authority services and general practitioners should be improved. I find tuberculosis clinics, through their medical staff, as co-operative as could be wished, but in contrast I have never had any communication from a midwife, or her superior officer, about a home confinement, nor do I get any direct communication from an infant welfare clinic about the vaccinations and protective inoculations done upon my patients. The school medical service gives me no direct information about tuberculosis tests and B.C.G. inoculations, and too often do they refer my patients to hospital without my knowledge and too seldom have I been told of positive findings discovered at school medical examinations. This failure to pass on information to the family doctor reduces the whole value of the service. I cannot remember that health visitors have ever communicated with me at all.

But co-operation can be carried too far, to the detriment of the confidential relationship between doctor and patient. I can only suppose it was witnesses representing local authorities who were reported thus in para. 63 of the Working Party's report: "Generally witnesses took the view that the public health or the school health department should be notified of discharges in agreed classes of case. At least they should be told the names of patients and dates of discharge; at best they should have a copy of the discharge letter to the general practitioner. It was urgent that notification should go out promptly to both and preferably before discharge; hospitals were often at fault in this respect. Most witnesses wanted health visitors to be in direct touch with the almoner and some with the ward-sister. A few wanted them to work directly with the consultant at case conferences or ward rounds in certain cases." This is bureaucracy on the ramp.

Given a fair chance to lead the team, I am confident that general practitioners would fulfil this responsibility.-I am, etc.,

$$
\begin{aligned}
& \text { London, S.W.1. } \\
& { }^{1} \text { An Inquiry into Health Visiting, 1956. H.M.S.O., London. }
\end{aligned}
$$

\section{Social Workers}

SIR,-As a consultant psychiatrist I welcome the letter of Dr. H. D. Chalke (Supplement, July 14, p. 53). I have always advocated that health visitors, by virtue of their basic nursing training, are the people of choice for the job of medico-social work. Parallel to this I would urge the creation of the mental health visitor's certificate, so that nurses with psychiatric experience, quite a number of whom are at present doing invaluable work for local authorities, could be suitably awarded and recognized as qualified in their particular field of social endeavour. They, like their general trained colleagues, have developed imperceptibly an intuitive understanding of the patient's difficulties and have had created within themselves an empathy which social science diplomats only acquire after many years of theory-blunting experience.

The psychiatric social worker is all too prone to class the health visitor (general or mental) as unqualified. It is all a question of orientation. The health visitor has an equal right to look askance when the social science graduate is accepted as an auxiliary into the medical profession. I would suggest that the Psychiatric Social Workers' Association and the Royal College of Nursing get together and hammer out a policy of mutual respect and friendly cooperation in helping the patient to a more satisfactory way of life.-I am, etc.,

Kirk Ella, E. Yorks.

JOHN MACKAY.

\section{Association Notices}

\section{Diary of Central Meetings}

August

1 Wed. Emergency Call Subcommittee, General Medical Services Committee, 2 p.m.

\section{Meetings of Branches and Divisions}

\section{SOUTH-WESTERN BRANCH}

The 111th annual meeting was held at the Hotel Bristol, Newquay, on June 9, when the new president, Air Vice-Marshal T. C Morton, was invested with the presidential badge and delivered an address on the hazards of tropical medicine. Later in the afternoon $\mathrm{Dr}$ Robert Forbes secretary of the Medical Defence Union, gave a talk on medical litigation. In the evening 100 Union, gave a talk on medical litigation. In the evening 100 members and their wives sat down to dinner at St. Rumon's
Hotel, and afterwards heard a lecture on the ascent of Mount Everest given by the principal guest, Dr. Michael Ward.

Correction.-In the report of the A.R.M. under the heading "Advance Payment of Compensation" (Supplement, July 14, p. 32) the name of Dr. J. H. Stranger (North Glamorgan and Brecknock) should replace that of Dr. A. Coleman. Under the heading "Employment of General Practitioners in Hospitals" (p. 33) the remarks attributed to Dr. St. G. B. D. Gray should have been attributed to Dr. H. F. Hiscocks (South-east Essex). 